\title{
Study on Spatial Distribution of Placenames Named in YI Nationality language in Yunnan Province Wujun $\mathrm{Xi}^{1 \text {, a }}$, Xiu Lu ${ }^{2, b}$
}

\author{
${ }^{1}$ School of Geography and Tourism Management, Chuxiong Normal University, Chuxiong, China \\ ${ }^{2}$ School of Tourism and Geography Science, Yunnan Normal University, Kunming, China \\ aabsxwj@163.com, b1037134652@qq.com
}

\begin{abstract}
Keywords: placenames named in YI nationality language, Yunnan province, spatial distribution Abstract. In order to explore spatial distribution of placenames of YI language in Yunnan province, the paper used Getis-Ord General G, spatial autocorrelation, clustering and abnormal values and Getis-Ord Gi* analysis methods to analyze it, then these conclusions could be drawn as follows. The spatial distribution of counties and cities that have placenames named in Yi nationality language presented high clustering. The high - high clustering areas and hot spots areas both included Kunming city, Chuxiong prefeture and Qujing city. The three areas were gathering areas of placenames named in Yi nationality language, and the gathering areas of Yi nationality activity.
\end{abstract}

\section{Introduction}

The Yi nationality mainly distributed in four south-west provinces contained Yunnan, Guizhou, Sichuan and Guangxi in China. The four provinces include a total of three Yi nationality autonomous prefectures and 19 Yi nationality autonomous counties [1].The YI nationality people in the long-term production and life produced many placenames named in YI nationality language. Placenames named in YI nationality language, named after the placenames which reflects the YI nationality's naming way of thinking and the YI nationality cultural connotation. It is also the YI nationality people identity and naming the geographic entities in language code [2].

Nowadays, the domestic studies of placenames named in YI nationality language mainly focused on linguistic studies [3] [4] [5], source test[6], meaning [7], location textual research [8], translation[9], Yi's claim to relation with placenames named in YI nationality language[10], Yi's placenames with the ecological environment[11], production mode in placenames[12] and the name[13] [14], etc. This article mainly discussed spatial distribution of placenames named in YI nationality language in Yunnan, to explore the leaving placenames mark and active regions by $\mathrm{Yi}$ nationality in the long historical changes.

\section{The Data Sources and Placenames Named in YI Nationality Language Confirmability}

Data from the dictionary of placenames of the People's Republic of China - Yunnan province [15]. It listed 2884 items of prefecture, county, town and important settlements. Among them, there are 288 placenames named in YI nationality language, accounting for 9.99\%. Placenames named in YI nationality language affirmation included different conditions: originally named in Yi language, now still in Yi language; originally named in Yi language, later they were simplified or refined; originally named in Yi language, later renamed. The first category occupied the most part numbers. The two later classes were small numbers. In addition, when placenames named in YI nationality language were confirmed, if there were 2 to 3 similar Yi placename on the same small area, only kept the palcename that administrative level was the biggest. If they were the same administrative level, then kept someone randomly. Such as big Mogu town and small Mogu, then kept big Mogu town, and Yulong town and Yulong street, then keep the Yulong town, etc. 


\section{Spatial Analysis of Placenames Named in YI Nationality Language in Yunnan Province}

There were 288 placenames named in YI nationality language, however, only 276 placenames named in YI nationality language had latitude and longitude coordinates. They were distributed in 75 counties or cities(figure 1).

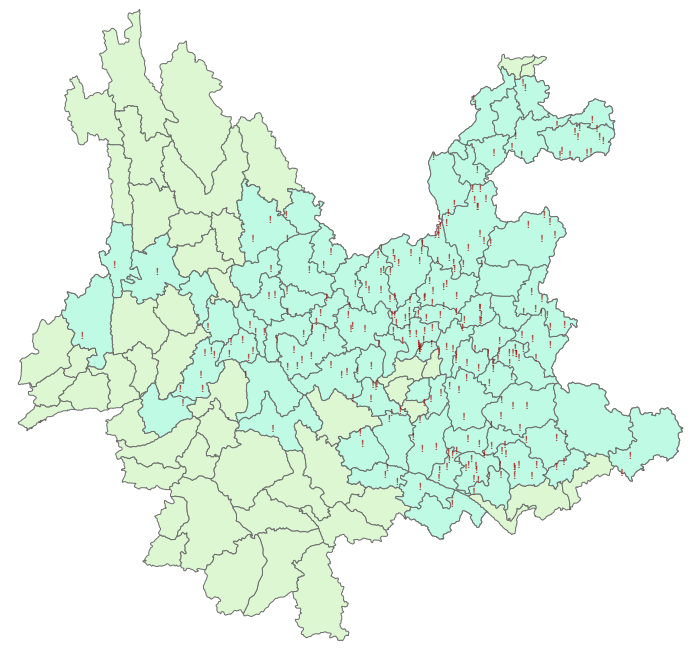

Figure 1 The spatial distribution of counties and cities that have placenames named in Yi nationality language in Yunnan province

The figure 1 showed that counties and cities that have placenames named in yi nationality language had continuous distribution, there did not exist enclaves. It meant that spatial distribution of placenames named in yi nationality language had continuity.

In addition, the counties and cities were mainly concentrated on eastern, northern, central and western in Yunnan province. Northwest and southwest existed obvious vacancy, the west was characterized by some vacancy.

\section{Getis-Ord General G Analysis of Placenames Named in Yi Nationality Language in Yunnan Province}

Getis - ord General G tools can measure the density of high value or low value to the specified area [16]. The formula is:

$$
\mathrm{G}=\frac{\sum_{i=1}^{n} \sum_{i=1}^{n} \omega_{i, j} x_{i} x_{j}}{\sum_{i=1}^{n} \sum_{i=1}^{n} x_{i} x_{j}}, \forall j \neq i
$$

In this formula, $\mathrm{x}_{\mathrm{i}}$ and $\mathrm{x}_{\mathrm{j}}$ are the attribute values of $\mathrm{I}, \mathrm{J} . \omega_{i, j}$ are the spatial weight values of $\mathrm{I}$, $\mathrm{J}, n$ is characteristic number, $\forall j \neq i$ is said that $\mathrm{I}, \mathrm{J}$ are not the same characteristics.

$Z_{G}$ calculation is as follows:

$$
Z_{G}=\frac{G-E[G]}{\sqrt{V[G]}}
$$

Among them,

$$
\begin{aligned}
& E[G]=\frac{\sum_{i=1}^{n} \sum_{j=1}^{n} W_{i, j}}{n(n-1)}, \forall j \neq i \\
& V[G]=E\left[G^{2}\right]-E[G]^{2}
\end{aligned}
$$




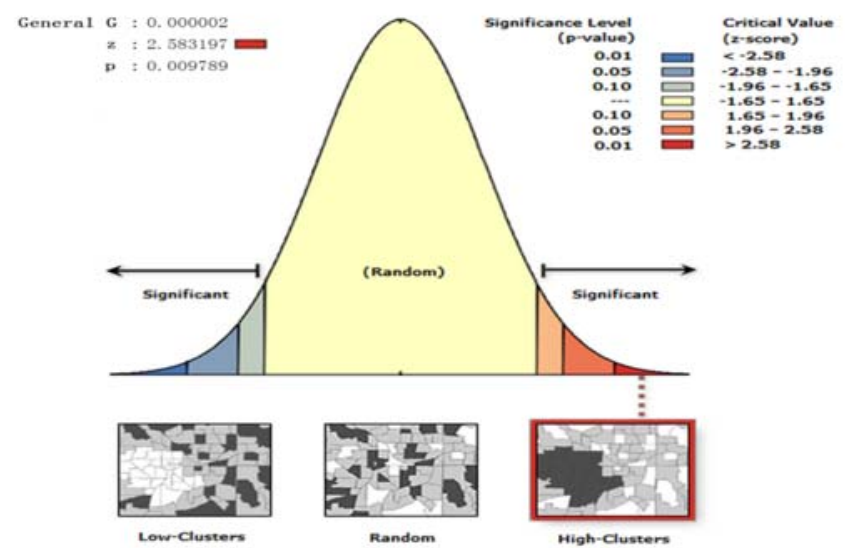

Figure 2 Getis-Ord General G Analysis Result

From the calculation result(figure 2) to the counties and cities with Getis-Ord General $G$ analysis method, the total overall distribution of the placenames named in yi nationality language presented high clustering model. Z score was of 2.58, p value was 0.007 , and it was the high degree of statistical significant. Z score was greater than 2.58 , that meant the possibility of generating the high clustering model randomly was less than $1 \%$.

\section{Spatial Autocorrelation Analysis of Placenames Named in Yi Nationality Language in Yunnan Province}

From the calculation result to the counties and cities with spatial autocorrelation analysis method, the Moran's index value was 0.15 , z score was 2.68 , p value was 0.007 and it was high significant degree. That meant the counties and cities showed a clustering distribution pattern, namely, the counties and cities didn't discrete or distribute randomly, but they had a strong clustering. It also suggested that the YI nationality's distribution was agminate.

\section{The Clustering and Abnormal Values Analysis of Placenames Named in Yi Nationality Language in Yunnan Province}

From the calculation result to the counties and cities with clustering and abnormal values analysis method, there existed two situations (high - high clustering and low - high abnormal values), didn't exist low-low clustering and high-low abnormal values, the rest were not significant. High - high clustering regions included Xundian county, Luquan county, Dongchuan District, Wuding county, Qujing city, Huize county, it meant that they all had relatively more placenames named in yi nationality language, so formed high - high clustering. Low-high abnormal value region was Zhanyi county, it shown that the surrounding counties and cities have relatively more placenames named in yi nationality language, and Zhanyi county had relatively few.

\section{The Getis-Ord Gi* Analysis of Placenames Named in Yi Nationality Language in Yunnan Province}

From the calculation result to the counties and cities with Getis-Ord Gi* analysis method, the whole area existed hot spots areas and cold spots areas, no significant areas. Thereinto, the hot spots areas with 99\% confidence level were Xundian county, Luquan county, Dongchuan district and Songming county. The former three areas also were high - high clustering areas. The hot spots areas with 95\% confidence level were Wuding county, Huize county, Zhanyi county and Fumin county. The former two areas also were high - high clustering areas. The hot spots area with $90 \%$ confidence level was none. On the other hand, the cold spots area with 99\% confidence level didn't exist, the cold spots area with 95\% confidence level was Dayao county. the cold spots areas with 90\% confidence level were Binchuan county and Yongsheng county. 


\section{Conclusions}

(1) Through the high/low clustering and spatial autocorrelation analysis, it was known that the spatial distribution of counties and cities that have placenames named in Yi nationality language presented high clustering.

(2) Through the clustering and abnormal values analysis, hot spots analysis, it could be learned that high - high clustering areas and hot spots areas both included Kunming city, Chuxiong prefeture and Qujing city. The three areas also in the range of standard distance distribution.

So, it could be seen as the "resonance" of three areas. There was no doubt that the three areas were gathering areas of placenames named in Yi nationality language, and the gathering areas of $\mathrm{Yi}$ nationality activity.

\section{Acknowledgements}

This research was financially supported by the Yunnan Social Science Fund Base Project (JD13YB17), Yunnan Excellent Young Teacher Project (natural geography) and Chuxiong Normal University key construction specialty Project(Human geography and urban and rural planning).

\section{References}

[1] Mouyuan YI. History of the Yi Nationality (Social Sciences Academic Press, Beijing 2007) (In Chinese).

[2] Wujun XI, Zuxin LIU. in: Chuxiong National Culture Forum(8th ed.). Yunnan University Press(2015).

[3] Zhaochun Wang. Guizhou Ethnic Studies. Vol. 3 (2010), p. 90-93 (In Chinese).

[4] Jiangwen LUO, Yaxin LUO. Journal of Yunnan Agricultural University (Social Science Edition). Vol. 2 (2014), p. 88-96 (In Chinese).

[5] Zhongliang PU. Minority Languages of China. Vol. 6 (1998), p. $42-48$ (In Chinese).

[6] Pin JIN, Jinping WANG. Journal of Sichuan Nationality Teachers College. Vol. 2 (2010), p. 26-28 (In Chinese).

[7] Jinsong LIU. GuiZhou Ethnic News, 2013-06-24B03 (In Chinese).

[8] Shengfu LI. Journal of Guizhou University for Ethnic Minorities (Philosophy and social science).Vol. 3 (2004), p. 105-107 (In Chinese).

[9] Tianyuan LI. Journal of Guizhou University for Ethnic Minorities (Philosophy and social science).Vol. 2 (2003), p. 84-86 (In Chinese).

[10] Zhongliang PU. Guizhou Ethnic Studies. Vol. 1 (2003), p. 159-165 (In Chinese).

[11] Tianyuan LI. Minority Languages of China. Vol. 1 (2002), p. 25-28 (In Chinese).

[12] Tingshuo YANG ,Tianyuan LI. Journal of Jishou University (Social Science Edition). Vol. 3 (2001), p. 63-67 (In Chinese).

[13] Shamadage. Journal of Xichang College(Social Science Edition).Vol. 1 (2005), p. 69-71 (In Chinese).

[14] Bamoayi. Ethno-National Studies. Vol. 6 (1987), p. 51-58 (In Chinese).

[15] Huirong ZHU. Placename Dictionary of the People's Republic of China - Yunnan Province (The Commercial Press, Beijing 1994) (In Chinese).

[16] Information on http://help.arcgis.com. 